УДК 514.181.22

DOI https://doi.org/10.32851/tnv-tech.2021.4.10

\title{
ГЕОМЕТРИЧНІ АСПЕКТИ ТРАНСЦЕНДЕНТНОГО ПЕРЕТВОРЕННЯ ПРОСТОРУ
}

\author{
Петрова А.T. - кандидат технічних наук, \\ доцент кафредри будівниитва, архітектури та дизайну \\ Херсонського державного аграрно-економічного університету \\ ORCID ID: 0000-0003-1482-2868
}

У статті розглядаються питання, пов'язані з вивченням можливостей деяких спеціальних координатних систем, які можуть застосовуватися під час проєктування поверхонь складної криволінійної форми. Криві поверхні застосовуються в багатьох галузях науки й техніки, зокрема машинобудуванні, будівництві, архітектурі та інших галузях знань, а також на виробництві. Конструювання складних кривих поверхонь може бути спрощеним, якщо під час проєктування застосовується геометричний апарат створення спеціальної координатної системи. У таких випадках геометричний апарат спеціальної координатної системи органічно зв'язується з геометрією та кінематикою поверхні, ш⿻о конструюється.

У практиці архітектурного проєктування є чимало прикладів застосування спеціальної координатної системи під час проєктування оболонок і різних криволінійних варіантів покриттів будівельних об'єктів та інших споруд. У зв'язку із ичм у роботі пропонується докладний опис геометричних перетворень прямокутної декартової системи координат на інші координатні системи. Будь-яку тривимірну систему координат представляємо у вигляді трьох умовних осей і трьох величин, щзо відкладаються на цих осях. Осі можуть бути прямолінійними чи криволінійними, а координати можуть бути лінійними величинами, кутовими, виражатися простим числом або взагалі бути якоюсь функцією деяких наперед заданих параметрів.

Будь-яка точка, лінія або навіть поверхня може використовуватися як початок відліку вибраних координат. Таким чином, отриману безліч координатних систем можна назвати узагальненою координатною системою. Водночас сутність будь-якої просторової координатної системи може бути представлена певною конгруениісю. Геометричним апаратом узагальненої координатної системи є будь-яка конгруенція прямих чи кривих ліній з урахуванням конкретних умов, шьо зв'язують параметри конгруениії. У визначення «узагальнена координатна система» включаються також відомі в математиці циліндрична та сферична координатні системи.

Ключові слова: координатні системи, геометричний апарат, перетворення простору, криві поверхні, узагальнена система.

\section{Petrova A.T. Geometric aspects of transcendent transformation of space}

This article discusses issues related to the study of the capabilities of some special coordinate systems that can be used in the design of surfaces of complex curvilinear shape. Curved surfaces are used in many branches of science and technology, including mechanical engineering, construction, architecture and other fields of knowledge and production. The design of complex curved surfaces can be significantly simplified if the geometric apparatus for creating a special coordinate system is used in the design. In such cases, the geometric apparatus of a special coordinate system is organically linked with the geometry and kinematics of the constructed surface.

In the practice of architectural design, there are many examples of the use of a special coordinate system in the design of shells and various curvilinear options for coatings of building objects and other structures. In this regard, this paper offers a detailed description of the geometric transformations of a rectangular Cartesian coordinate system into other coordinate systems.

Any three-dimensional coordinate system is represented in the form of three conditional axes and three quantities plotted on these axes. The axes can be rectilinear or curvilinear, and the coordinates can be linear quantities, angular, expressed as a prime number or in general by some function of some predefined parameters or any function at all. Any point, line, or even surface can be used as the origin of the selected coordinates. Thus, the resulting set of coordinate systems can be called a generalized coordinate system. 
At the same time, the essence of any spatial coordinate system can be represented by a certain congruence. The geometric apparatus of a generalized coordinate system is any congruence of straight or curved lines, taking into account the specific conditions connecting the parameters of the congruence. The definition of "generalized coordinate system" includes the well-known cylindrical and spherical coordinate systems.

Key words: coordinate systems, geometric apparatus, transformation of space, curved surfaces, generalized system.

Вступ. Конструювання складних технічних форм посідає вагоме місце у процесі проєктування різних кривих поверхонь у багатьох галузях науки й техніки, зокрема машинобудуванні, будівництві та архітектурі. Проблема полягає в тому, що для відтворення будь-якої криволінійної поверхні в реальних умовах необхідно мати можливість аналітичного опису поверхні, що конструюється, або графічний алгоритм побудови іiі каркаса.

Постановка завдання. На стадії проєктування завдання проєктувальника полягає у визначенні геометричного апарату конструювання, який дає можливість застосовувати деякий спосіб утворення каркасу поверхні. Сучасні геометричні методи конструювання складних криволінійних поверхонь дають можливість вибору, зокрема вибору спеціальної координатної системи, застосування якої полегшує процес проєктування.

Застосування в геометричному апараті проєктування спеціальних координатних систем приводить до отримання графічного алгоритму конструювання (побудови) каркасу складної поверхні або іiі аналітичного опису, що дає можливість обчислити координати будь-якої точки поверхні, що проєктується. Схожі методики застосовувалися у працях В.С. Михайленка, С.М. Ковальова та інших авторів [1;2].

Виклад основного матеріалу. Змінюючи умови, що характеризують параметри променя та точки на ньому різних конгруенцій, можна сконструювати безліч просторових координатних систем, окремими випадками яких є розглянуті в геометрії відомі циліндрична та сферична системи координат. Зазначені системи входять до загальної схеми утворення, узагальненої координатної системи, побудованої за принципом трьох осей і трьох координат, що їм відповідають. Наявність загальної схеми дає змогу за умови задання об'єкта в одній системі координат трьома координатами цими ж координатами в іншій системі задавати новий об'єкт, кожній точці якого можна поставити у відповідність точку вихідного об'єкта. За цим принципом засновані різні координатні перетворення простору.

Залежно від розглянутих вище факторів, що впливають на вигляд узагальненої координатної системи, вибраної як перетворена, можна отримати різні перетворення простору: алгебраїчні та трансцендентні, одно- й багатозначні. Вигляд і параметри конгруенції, що застосовується як перетворена система координат, вибираються залежно від того, яке перетворення необхідно виконати для практичного вирішення певної конкретної задачі під час конструювання складних кривих поверхонь, зокрема оболонок [2].

Розглянемо процес перетворення декартової системи координат на узагальнену в іншому аспекті. Як уже було сказано, три координати, що характеризують об'єкт в одній системі, в іншій системі задають новий об'єкт, тобто за постійних координатних величин змінюються умови їх відліку або геометричний зміст координатних осей. Можна припустити, що з позиції фізики цей процес $є$ деформацією вихідної координатної системи та взагалі координатного простору, що 3 геометричної позиції має назву координатного перетворення простору. Вид 
геометричного перетворення залежить від виду та ступеня деформації простору. Завданням певних характеристик деформації координатної системи встановлюється відповідність точок перетвореного об'єкта точкам вихідного об'єкта.

Приклад. Задаємо у прямокутній декартовій системі координат $O X Y Z$ точку $A(x, y, z)$, а як узагальнену координатну систему візьмемо конгруенцію $K \Gamma(1,1)$ прямих ліній, директрисами яких $\epsilon$ дві прямі - $a, b$ загального положення. Призначимо умови відліку координат узагальненої координатної системи. Точки 0 Oi на прямих $a, b \in$ початком відліку параметрів променя. Параметрами променя нехай будуть координати $x, y$ точки, що перетворюється, які відкладаються, відповідно, на директрисах $a, b$ (див. рис. 1 ).

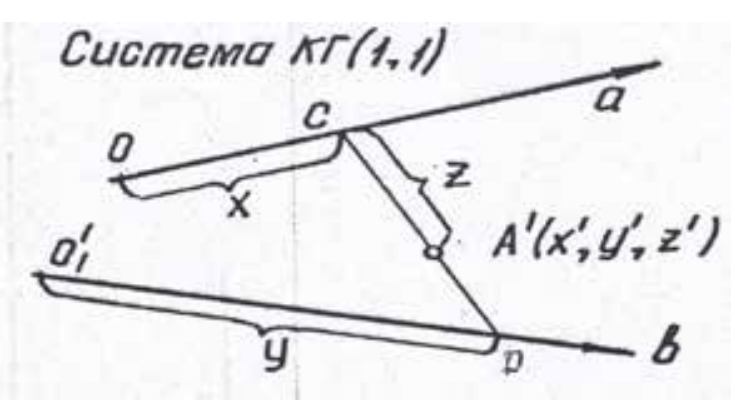

Рис. 1. Перетворення точки А в системі конгруенції

Параметром точки на промені конгруенції нехай буде координата $z$ точки $A$, що відкладається на промені від прямої $a$. Координати точки $A$, що перетворюється, виділяють єдиний промінь конгруенції - $C D$, на якому знаходиться точка $A$, що відповідає заданій точці $A$. За таким же принципом на рис. 2 поверхня $\Phi$ перетворена в тій же узагальненій координатній системі, утвореній із конгруенції $K \Gamma(1,1)$, за тих же умов відліку координат, на нову поверхню $\Phi$.

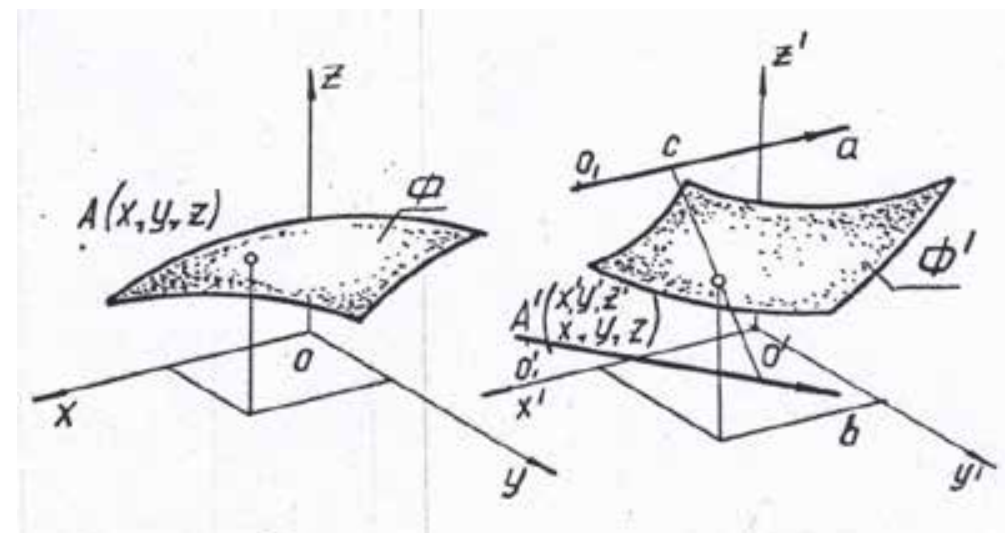

Рис. 2. Перетворення поверхні Ф на поверхню $Ф$

У такій узагальненій координатній системі рівняння отриманої поверхні не змінює вигляд: $F(x, y, z)=0$. Для запису рівняння отриманої перетвореної поверхні декартової системи координат необхідно мати формули переходу координат узагальненої системи в координати декартової системи, тобто: 


$$
X=f(x, y, z, u, v), Y=f(x, y, z, u, v), Z=f(x, y, z, u, v),
$$

де $u, v$ - параметри конгруенції.

Вище було сказано, що циліндрична координатна система є окремим випадком узагальненої системи координат, утвореної з конгруенції $K \Gamma(1,1)$ горизонтальних прямих. Однією директрисою конгруенції є вертикальна пряма, а іншою - нескінченно віддалена пряма (горизонтальна площина паралелізму). Параметрами променя конгруенції $є$ величини $i, z$, параметром точки на промені - величина $\rho$. Таке перетворення, коли лінійним координатам вихідної системи ставляться у відповідність кутові координати, можна назвати трансцендентним перетворенням простору.

Розглянемо одне з трансцендентних перетворень простору, коли декартова система координат перетворюється, тобто деформується в циліндричну. У такому трансцендентному перетворенні замість лінійної координати $x$ варто задаватися кутовою координатою $\varphi$, дві інші лінійні координати $-z$ та $y=\rho-$ залишаються незмінними. Такому перетворенню, що розглядається як деформація простору, можна надати фізичного змісту, а саме: якщо взяти гнучку фронтальну площину, прикріпити до неї жорсткі стержні, як показано на рис. 3, а в отвори на вільних кінцях стержнів просмикнути нитку, що є віссю $O X$, то під час стягування нитки стержні розташуються радіально, пряма $A B$ стане дугою кола радіуса $\tau$, що дорівнює довжині стержнів, а площина $\sum$ здеформується в циліндричну поверхню. При цьому якщо довжина $\ell=2 \pi \tau$, то циліндр буде замкнутим. Рівняння площини виражене як $\sum y=a$, а рівняння отриманої перетвореної поверхні $-\rho=a$.
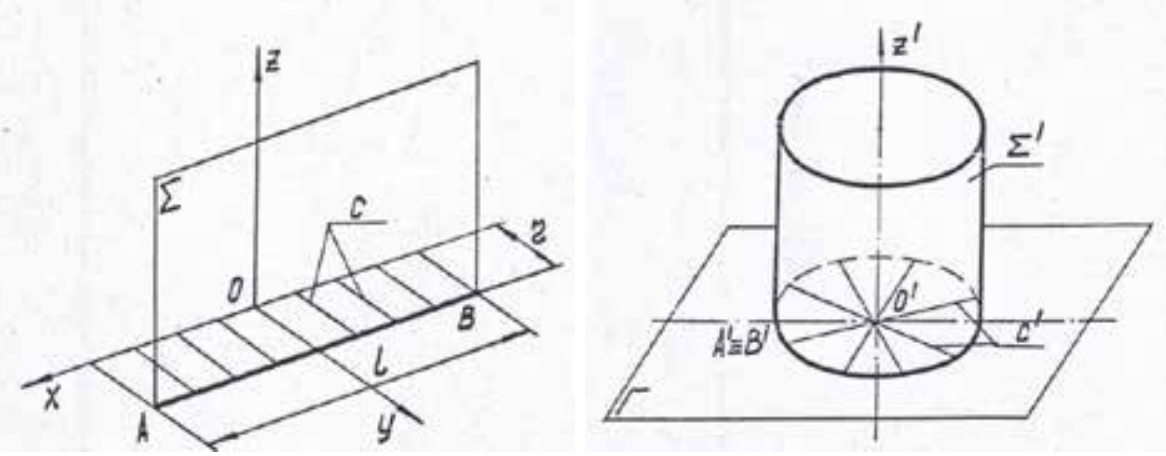

Рис. 3. Фізичний сенс трансиендентного перетворення простору як його деформації

Для визначення ступеня деформації простору в цьому перетворенні необхідно встановити однозначну залежність між лінійною координатою $x$ та кутовою координатою $\varphi$ (радіан).

Розглянемо, як деформується в цьому перетворенні пряма лінія $M N$, що проходить через початок координат горизонтальної площини, рівняння цієї прямої виражене як $y=\kappa x$. У цьому трансцендентному перетворенні цій прямій відповідає крива, рівняння якої $-\rho=a \varphi$, де координата $\rho=y$, а координата $x$ перетворюється на кутову координату $\varphi$. Це рівняння описує спіраль Архімеда, що розташована в горизонтальній площині. Вертикальна площина, проведена через вихідну пряму $M N$, деформується в перетворенні на циліндричну поверхню, у якій напрямною лінією $є$ спіраль Архімеда. На рис. 4 показані варіанти деформації перетворення прямих ліній і площини декартової системи координат у циліндричні поверхні, що направляють, відповідно, прямі лінії, перетворені на спіралі 
Архімеда. Очевидність трансцендентності розглянутого перетворення, як деформації простору, підтверджується ідентичністю алгебраїчного запису рівняння прямої лінії $y=\kappa x$ та рівняння спіралі Архімеда $\rho=a \varphi$.
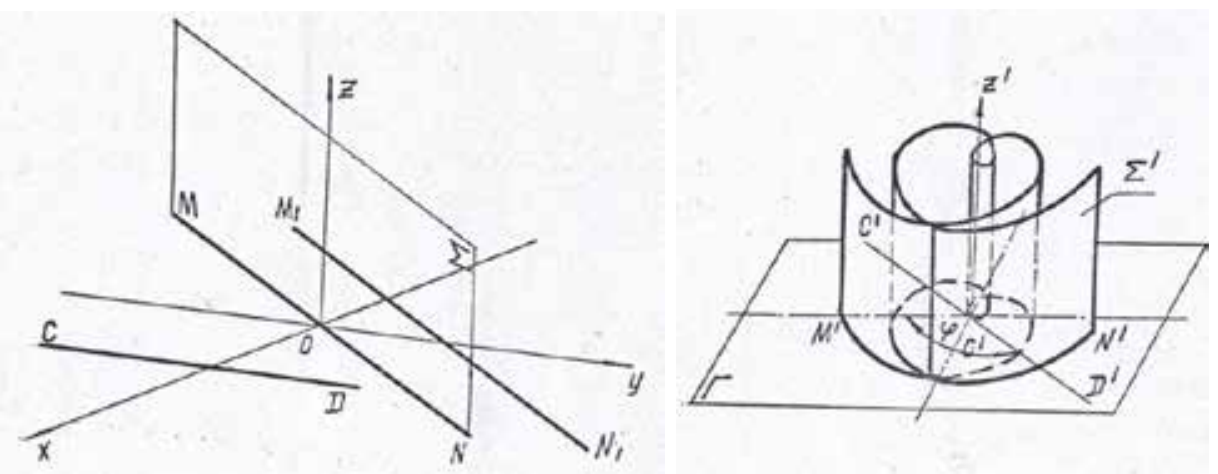

Рис. 4. Перетворення (деформація) прямих ліній і площчини на спіралі Архімеда та ичиліндричну поверхню

Деформацію інших геометричних об’єктів, наприклад площини загального положення, у цьому перетворенні розглянемо на прикладі площини загального положення $\sum$ (див. рис. 5). Наносимо на площині два сімейства ліній - фронтальні та профільні. Сімейство фронтальних ліній вихідної площини перетворюється на каркас гвинтових ліній різних параметрів, а сімейство профільних прямих перетворюється на прямолінійні утворюючі лінійної поверхні, у якій однією напрямною лінією є вісь $O Z$, а другою напрямною є спіраль Архімеда. На отриманій поверхні можна виділити ще один каркас зі спіралей Архімеда, отриманий перетворенням горизонталей вихідної площини.

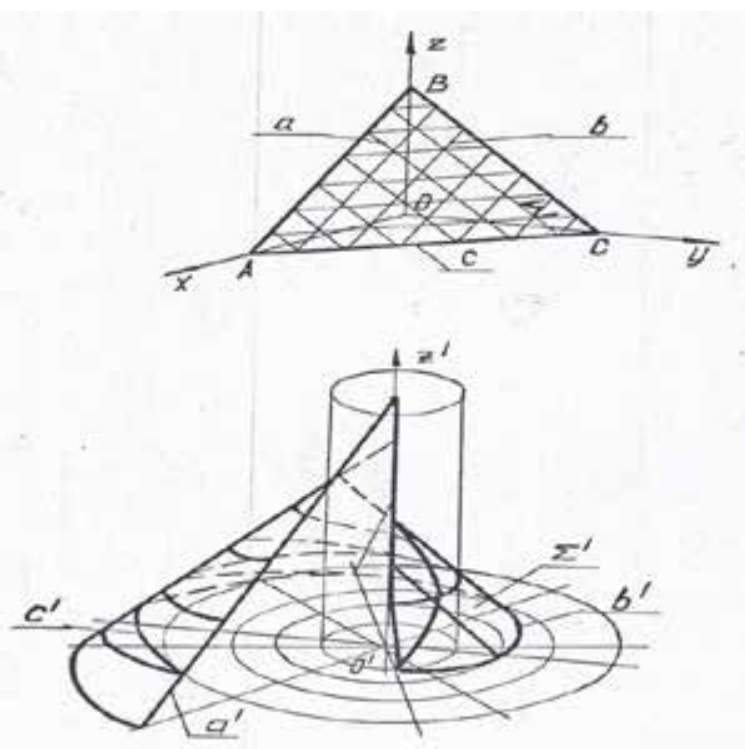

Рис. 5. Трансиендентне перетворення площиини загального положення на криву лінійну поверхню 
Висновки. У роботі ми спробували навести узагальнену схему утворення тривимірних координатних систем із погляду деформації простору як його перетворення, зокрема й цього трансцендентного перетворення. Наведені геометричні дослідження дали можливість надалі вивчити характеристики, властивості й можливості цього трансцендентного перетворення вихідних об'єктів - пласких і просторових кривих ліній - на відповідні перетворені лінії та поверхні.

Результати наведених досліджень цього трансцендентного перетворення можуть застосовуватися під час конструювання складних кривих поверхонь у процесі розроблення алгоритму їх графічної побудови або аналітичного опису для визначення координатних величин будь-якої точки кривої поверхні, що конструюється.

\section{СПИСОК ВИКОРИСТАНОЇ ЛІТЕРАТУРИ:}

1. Михайленко В.Е., Обухова В.С., Подгорный А.Л. Формообразование оболочек в архитектуре. Киев: Будівельник, 1972. 207 с.

2. Михайленко В.Е., Ковалев С.Н., Умаров М.У. Конструирование поверхностей тонкостенных оболочек. Прикладная геометрия и инженерная графика. 1982. Вып. 33. С. 3-5.

\section{REFERENCES:}

1. Mikhaylenko, V.E., Obukhova, V.S., Podgornyy, A.L. (1972). Formoobrazovanie obolochek varkhitekture [Shaping shells in architecture]. Kyiv: Budivelnyk [in Russian].

2. Mikhaylenko, V.E., Kovalev, S.N., Umarov, M.U. (1982). Konstruirovanie poverkhnostey tonkostennykh obolochek [Surface design of thin-walled shells]. Prikladnaya geometriya i inzhenernaya grafika - Applied Geometry and Engineering Graphics, issue 33, pp. 3-5 [in Russian]. 